degree to the public, but that certainty of this risk is not sufficient to detain him in hospital. Further, we would argue that the psychiatric professional body needs to debate within itself about the role of forensic psychiatrists in protecting the public, and that there need to be professionally agreed guidelines about risk assessment. (Monahan, 1992, 1993). Finally, in the event of $\mathrm{Mr} \mathrm{X}$ offending in the future, we would claim that there is no causal responsibility where there is no certain or reasonably certain foreknowledge.

In a similar case, $\mathrm{Mr} \mathrm{X}$ was admitted to a Special Hospital. He remains there. He would like to leave.

\section{References}

BRTTAIN, R. (1970) The sadistic murderer. Medictne, Sctence and the Law, 10, 198-207.

MONAGHAN, J. (1992) Mental disorder and violent behaviour. American Psychologist, 47, 511-521.

- (1993) Limiting therapist exposure to Tarasoff liability. American Psychologist, 48, 242-250.

ScoTt, P. (1977) Assessing dangerousness in criminals. British Journal of Psychiatry. 131, 127-142.

Gwen Adshead, Lecturer, Department of Forensic Psychiatry, Institute of Psychiatry, De Crespigny Park, London SE5 8AF and Jeanette Smith, Senior Registrar, Fromeside Clinic, Blackberry Hill, Bristol BS16 1ED

\title{
Perception of equivalent doses of neuroleptic drugs
}

\author{
R. Mullen, A.W. Caan and S. Smith
}

\begin{abstract}
An anonymous questionnaire was sent to 67 senior and junior psychiatrists enculing about their perception of equivalent antipsychotic dosages of three commonly used neuroleptic drugs. Thitty-one questionnaires were retumed and revealed a wide variation in percelved potencies for the specilic drugs. Increased experience in psychiatry was not associated with a decreased variation. On average clinicians saw haloperidol and liupenthixol decanoate as substantially less potent, relative to chiorpromazine, than the avallable literature would suggest.
\end{abstract}

The adverse consequences of excessive or inadequate dosage of neuroleptics are well recognised. Despite gaining scant empirical attention, the problem of choosing the correct dose of an antipsychotic drug in a clinical setting is common. Appropriate dosing requires a recognition that antipsychotic drugs vary in potency.

Except for some atypical antipsychotic drugs, it is accepted from radioligand studies that effective antipsychotics displace ligands from dopamine receptors with a facility that correlates highly with their antipsychotic potency (Peroutka \& Snyder, 1980). From this robust psychopharmacological finding, the concept of equivalent doses of different neuroleptics arises.

Recent publicity about high rates of side effects and occasional deaths on high doses have brought the issue of dosage into focus. It has been postulated (Krakowski et al, 1993) that some patients receive high doses of neuroleptics because of ignorance about the efficacy of low doses. Our concern here is that clinicians may not be fully aware of what constitutes a high, or a low, dose of these drugs.

The study reported here sought to audit clinicians' knowledge of neuroleptic equivalence.

\section{The study}

We used a postal questionnaire survey. Sixtyseven psychiatrists working at junior and senior level at the Bethlem Royal \& Maudsley Special Health Authority, with responsibilities in adult psychiatry, were sent a vignette involving a patient transferred from chlorpromazine (the usual reference drug for antipsychotic equivalence) to other widely used neuroleptics. The vignette read:

A young man with chronic schizophrenia is well stabilised on a total daily dose of $500 \mathrm{mg}$ of chlorpromazine. Because of oversedation, you wish to substitute a different neuroleptic. Please indicate what dose or dose range you would consider to be of equivalent antipsychotic potency for the following drugs: 
Drugs specified were haloperidol and trifluoroperazine (both as total daily dose) and flupenthixol decanoate (as an intramuscular injection every two weeks). Respondents were requested not to refer to any other source before answering. They were also asked to indicate how long they had practised in clinical psychiatry and invited to comment further if they wished. The questionnaires were returned anonymously.

Data were entered on a database using the Statistical Package for Social Sciences, and parametric and non-parametric tests used to evaluate possible relationships between suggested doses and experience. Comparisons were made with the suggested equivalents in Brttish National Formulary (BNF) and the ABPI Pharmaceutical Industry Data Sheet Compendium (Association of the British Pharmaceutical Industry, 1990).

\section{Findings}

Usable data were obtained from all forms returned (response rate $46 \%$ ). The range of equivalent doses suggested (mean, median and inter-quartile range) was haloperidol 5-100 $\mathrm{mg}$ (31, 25, 15-41 mg; trifluoperazine 5-60 mg (26, $25,15-30 \mathrm{mg}$ ); and flupenthixol decanoate 20$300 \mathrm{mg}(88,60,40-100 \mathrm{mg})$. The range of experience in psychiatry was six months to ten years (mean four years). Four respondents commented that their usual practice was to look up the dose equivalents in the formulary.

Years in practice showed no significant correlation (product-moment) with any dose estimate (flupenthixol decanoate, $r=0.08$; haloperidol, $r=0.30$; trifluoperazine, $r=0.27$ ), nor did one-way analysis of variance find any significant effect of experience on the range of estimates made. Neither the least experienced doctors (six months to one year, $n=4$ ) nor the most experienced (more than five years, $n=7$ ) differed significantly from the others on any dose estimates (Student's $t$-test).

Doses suggested were highest for flupenthixol decanoate and lowest for trifluoperazine (Kendall's coefficient of concordance, $W=0.51$, $P<0.0001$ ). However, there was no consistent scaling between doses (product-moment correlations). Haloperidol+trifluoperazine, $r=0.27$, $P=0.16$; haloperidol+flupenthixol decanoate, $r=0.25, \quad P=0.20$; trifluoperazine+flupenthixol decanoate, $r=0.45, P=0.02$.

\section{What are equivalent doses of neuroleptics, really?}

On the face of it, this is a straightforward question. As neuroleptic drugs (clozapine excepted) are held to be of equivalent antipsychotic effcacy, the idea that different doses of different drugs may be equivalent presents no intellectual problem. However, the clinical utility of these drugs lies not only in their effects on narrowly defined psychotic phenomena but also in effects such as sedation, anxiolysis and immediate behavioural effects. Such effects are often the immediate goal of prescribing, for example, when a patient becomes agitated and violent. These actions may not be directly related to the effects of the drugs on central dopamine systems. Forster (1989) has suggested that these factors may account for the poor agreement about the equivalent dosage of haloperidol, noting also that the relationship between haloperidol and chlorpromazine is unlikely to be linear.

Such caveats aside, there is general agreement in the literature about what doses are equivalent. The BNF 25 (1993) offers the following as equivalent total oral daily doses: chlorpromazine $100 \mathrm{mg}=$ haloperidol $2-3 \mathrm{mg}=$ trifluoperazine $5 \mathrm{mg}$. The authors have found this to be in accordance with other sources. However, otherwise detailed formularies rarely suggest equivalent doses for depot neuroleptics. The BNF 25 (1993) has a useful conversion table for clinicians changing a patient from one depot to another, but their guidance offered concerning replacement of oral with depot neuroleptics makes no reference to equivalence of antipsychotic effect. Schulz et al (1989) offer advice on this, based on detalled pharmacokinetics. The ABPI (1993-94) indicates that $8 \mathrm{mg}$ of flupenthixol decanoate, two weekly, is equivalent to $100 \mathrm{mg}$ daily of chlorpromazine. From the above, we can assume chlorpromazine $500 \mathrm{mg}$ daily= haloperidol 10-15 mg daily=trifluoperazine $25 \mathrm{mg}$ dally=flupenthixol decanoate $40 \mathrm{mg}$ two weekly to be equivalent.

How do these equivalences compare with the results of our study? On average, our respondents thought that chlorpromazine is approximately two to three times more potent in relation to haloperidol and flupenthixol decanoate than the literature suggests. Mean dose of trifluoperazine was in good accordance with recommendations. For the chlorpromazine equivalents of the three drugs, one doctor gave doses all consistent with the formularies' model $(15,25$ \& $40 \mathrm{mg}$ ), none of the 31 gave consistently lower values for all three equivalents and ten (33\%) gave consistently higher doses for all three drugs. If consistent miscalculation were present, it was significantly more likely to be overestimating doses than underestimating (sign test $P<0.001)$. Overestimates were especially common for doses of flupenthixol (67\%) and haloperidol (73\%), compared with trifluoperazine (41\%). While a (weak) correlation appeared to exist between trifluoperazine and flupenthixol 
doses, linear regression suggested that any possible scaling was from $1: 2.1$, not $1: 1.6$ as in the equivalence suggested above.

\section{Comment}

This study, crude in design and execution, achieved a low response rate. It would be ill advised to use the results to come to firm conclusions about the psychopharmacological acumen and prejudices of the whole group of clinicians surveyed. The wide range of doses perceived as equivalent is striking. It commands attention as a disquieting finding, difficult to explain in terms of the method. For example, the high concordance across respondents shows a non-random ranking of the drugs, i.e. some knowledge of their properties. However, the quantitative relationships were not understood by most respondents, and doctors were more likely to overestimate consistently rather than underestimate consistently. In this era of concern about prescription of high doses of neuroleptics, training in rational prescribing is of recognised importance. This study indicates that such education may currently be inadequate.

These findings may not necessarily reflect neuroleptic prescribing nationally. Further studies, perhaps comparing different centres, are needed. We agree with the conclusion of Rey et al (1989), that the concept of equivalence is clinically useful and offers the best basis for predicting antipsychotic effect.

\section{Acknowledgement}

We are indebted to Adrienne Edwards, Chief Pharmacist, Special Health Authority, Robin Murray, Professor of Psychological Medicine and Michael Crowe, Chairman of the Medical Audit Committee, for their advice on the manuscript.

\section{References}

ASSOCIATION OF THE BRTISH PHARMACEUTICAL INDUSTRY (1990) ABPI Data Sheet Compendium 1993-94, 695.

British National Formulary (1993) 25, 149-155.

FORSTER, P. (1989) Neuroleptic equivalence. The Pharmaceutical Journal. September, 431-432.

KRAKOWSK, M.I., KUnz, M., CZOBAR, P. \& VOLAVKa, J. (1993) Long-term high-dose neuroleptic treatment: who gets it and why? Hospttal and Community Psychiatry, 44, 640644.

PEROUTKA, S.J. \& SNYDER, S.H. (1980) Relationship of neuroleptic drug effects at brain dopamine, serotonin. a-adrenergic, and histamine receptors to clinical potency. American Journal of Psychiatry, 137, 1518-1522.

REY, M.. SChulz, P., COSTA, C., Dick, P. \& Tissor, R. (1989) Guldelines for the dosage of neuroleptics. 1: Chlorpromazine equivalents of orally administered neuroleptics. International Clinical Psychopharmacology. 4, 95-104.

Shulz, P., REY, M.. Dick, P. \& Tissor, R. (1989) Guidelines for the dosage of neuroleptics. 2: Changing from dally oral to long acting injectable neuroleptics. International Clinical Psychopharmacology. 4, 105-114.

R. Mullen, Clinical Research Worker, A.W. Caan, Audit Research Co-Ordinator; and S. Smith, Registrar in Psychiatry. The Maudsley Hospttal, London SE5 8AZ 